\title{
Understanding the Role of Interaction From Linguistic, Affective, and Social Perspectives
}

Guang Xu

This study was conducted to broaden the scope of studies on interaction. It examined the role of interaction in terms of linguistic, affective, and social aspects. A questionnaire was administered and intensive interviews conducted to reveal the reality of communication between Chinese ESL students and Canadian native English speakers and how students made sense of their interaction with native speakers. Some linguistic benefits of interaction were found. A dynamic relationship between anxiety/confidence and interaction was identified. However, a significant gap between students' attitude/desire and their interaction intensity was exposed, which was explained by social support and other factors.

Cette recherche avait comme objectif d'élargir l'envergure des études sur l'interaction. Elle a porté sur le rôle de l'interaction en termes d'aspects linguistiques, affectifs et sociaux. Un questionnaire et des entrevues intensives ont révélé la réalité de la communication entre les étudiants chinois en ALS et les Canadiens locuteurs natifs d'anglais, et ont fourni des données sur la perspective des étudiants quant à leur interaction avec les locuteurs natifs. Nous avons identifié quelques avantages linguistiques découlant de l'interaction, ainsi qu'un rapport dynamique entre l'anxiété/la confiance et l'interaction. Toutefois, un écart significatif entre l'attitude/le désir des étudiants et l'intensité de leur interaction s'est révélé; celui-ci s'explique par l'apppui social, entre autres facteurs.

\section{Background}

\section{The Study of Interaction in SLA}

Interaction is defined as communication between people, particularly when they are negotiating meaning in order to prevent a breakdown in communication (Ellis, 1999). Researchers tend to believe that interaction in the second language (L2) plays a role in language acquisition; yet vast discrepancies exist in the reasons and the mechanism. Part of the research that upholds the role played by interaction is based on the theory of comprehensible input. Krashen (1981) hypothesized that we acquire language by understanding what is a little beyond our current level, with the aid of the extralinguistic context or of our knowledge of the world. Given the evidence that exposure 
to a language is not sufficient for acquisition, Krashen proposed comprehension as the essence of the acquisition process.

However, it is difficult to identify the relationship between comprehension of meaning in L2 input and the internalization of L2 forms. By investigating the procedures in which native speakers (NSs) and non-native speakers (NNSs) engage in order to avoid or repair breakdowns in their conversation, Long (1983) claimed that input is made comprehensible through modifying interactional structures rather than through simplifying linguistic input. Interaction in the L2 is argued to facilitate acquisition by allowing learners to "notice the gap" between their command of the language and to correct their use to make it target-like (Schmidt \& Frota, 1986). The term negotiation has been adopted to refer to this specific form of interaction that involves gap-noticing and repairing.

During negotiation, both learners and interlocutors can check the comprehensibility of their own speech. They can request clarification, confirmation, or reiteration of what the others have said, and they can modify their sounds, structures, and vocabulary toward greater comprehensibility. Comprehension difficulty allows learners to realize that linguistic modification is necessary and in turn to focus their attention on forms that would otherwise be unnoticed (Varonis \& Gass, 1985). Therefore, White (1987) claimed that what is necessary for L2 development is not comprehensible input, but incomprehensible input. By this she suggested that it is the incomprehensible part of the conversation that triggers modifications to language and finally becomes an impetus for learners to recognize the inadequacy of their interlanguage system. In this vein, Pica (1994) argued a powerful role for negotiation in L2 learning, suggesting that negotiation is a process that not only emphasizes the communication of message meaning, but also provides an opportunity to focus on message form. And studies (Long, 1996; Mackey, 1999; Nation, 2001) have indicated that interaction can enhance or increase the pace of acquisition.

Another part of research that upholds the role of interaction in acquisition builds its contention on comprehensible output. For example, Swain (1985) claimed that it is often possible for learners to understand the meaning of L2 without grasping its morphosyntax. However, in order to be comprehensible in extended discourse, learners must obtain a certain level of output grammaticality. Thus through producing language, either spoken or written, language acquisition may occur.

Despite the strong argument for interaction, negotiation, and output in linguistic development, some researchers have shown through data that when learners communicate in the L2, they fail to notice non-target-like features in their interlanguage unless these are indicated explicitly (Schmidt \& Frota, 1986). It is has also been suggested that negotiation may be beneficial only to certain learners (Mackey \& Philp, 1998; Philp, 2003). Ellis (1995) 
provided an empirical example of acquisition without output, and Krashen (1994) noted case studies that confirmed that people can develop extremely high levels of language and literacy competence with no language production (interaction) at all.

To date research has confirmed that interaction is potentially facilitative to language acquisition, but there is not enough evidence to suggest that learners internalize input and develop their interlanguage system through interaction. Indeed, interaction entails linguistic, social, and cognitive processes at one time, all of which have been claimed to play a role in successful L2 learning (Pica, 1992). However, regardless of the varied stands that researchers have taken with respect to L2 interaction, most have limited their study to looking only into the linguistic process.

\section{Cognitive and Social Perspectives on SLA}

Gardner (1983) referred to the learning of a second language as "a social psychological experiment" (p. 220). Through the socio-educational model (Gardner, 1979, 1983, 1985) of SLA, he postulated that language-learning is a dynamic process in which some affective variables influence language achievement, and conversely, the achievement and experience of learning the language can have an effect on affective variables. Gardner assigned extra emphasis to the role that affective variables play in SLA. Such variables are argued to be important because they direct people to work harder in both formal and informal language contexts. In accordance with Gardner's hypothesis, Schumann (1994) answered the question of Where is cognition? from a neural perspective that, "it is in the brain, intimately integrated with the neural mechanisms for affect" (p. 240). Schumann explained that the cognitive process is known as a stimulus appraisal system, where the brain emotionally modulates cognition and directs behavior. Stemming from this notion, the study of Willingness to Communicate (WTC) is particularly fruitful. Studies confirmed two key predictions from the pyramid model of WTC (MacIntyre, Dörnyei, Clément, \& Noels, 1998). First, lower anxiety and higher perceived competence are correlated with higher levels of WTC. Second, greater L2 communication experience would lead to higher levels of WTC (Baker \& MacIntyre, 2000; MacIntyre, Baker, Clément, \& Donovan, 2003).

Yashima and associates (Yashima, 2002; Yashima, Zenuk-Nishide, \& Shimizu, 2004) jointly used the socio-educational model and the WTC model to investigate relations between L2 learning and communication with Japanese EFL students. The findings were essentially congruent for the two predictions. However, Yashima failed to identify a direct path from motivation to WTC, which suggested that for EFL students in Japan, motivation alone was not sufficient to induce WTC and communication. Comparably, other studies (MacIntyre, Baker, Clément, \& Conrod, 2001) have revealed 
that students had higher L2 WTC in the immersion classroom than in social settings outside the classroom, which could be attributed to the need for additional effort to find those settings. Thus researchers suggested that it is necessary to have an interlocutor for authentic communication.

The importance of significant others or subjective norms (Ajzen \& Fishbein, 1980) was further confirmed by a study that considered both contextual and individual difference variables in L2 use with Anglophone (majority) and Francophone (minority) students attending a Canadian bilingual university (Clément, Baker, \& MacIntyre, 2003). Then, as MacIntyre (2003) concluded, "if WTC represents the decision to initiate communication, given the choice, then communication by minority groups learning a second language with high ethnolinguistic vitality might not be governed by WTC, based on the absence of choice."

Norton (2000) radically criticized the premises that language-learners can choose under what conditions they will interact with the L2 community and that language-learners' access to L2 is a function of individual motivation (Gardner \& MacIntyre, 1992). Norton's assertion is based on her longitudinal case study with adult immigrant women in Canada. The study revealed that for many immigrants, the linguistic environment represents inequitable relations of power and even hostility, with native speakers "more likely to avoid [learners] than negotiate meaning with them" (p. 113). She pointed out that most SLA theories recognize the need for learners to produce the language, but one cannot assume egalitarian relationships between learners and natives, and that a learner's motivation to speak is mediated by other investments that may conflict with the desire to speak. This critical perspective is valuable to the study of interaction, because instead of considering learners only as individuals, it emphasizes their histories and social connections.

\section{Implications of the Present Study}

So far the role of interaction has been examined from the linguistic perspective. Findings have suggested that it plays only a facilitative role in acquisition, and the conclusion remains ambiguous. However, the cognitive and social processes entailed were consequentially analyzed when trying to define the role of interaction in SLA. Therefore, I decided to carry out a study to examine how variables of language-affective and social—would jointly influence students' interaction with NSs, and conversely how this interaction would affect those variables. The present study is distinct in three aspects: (a) It attempts to integrate the affective and social dimensions into the present dominantly linguistic study of the role of interaction in SLA. (b) The qualitative method is particularly appropriate for exploring the affective and social facets of interaction. (c) The target group is Chinese ESL students in Canada, who have a considerable population in Canadian institutes, but have not yet attracted corresponding interest in research. 
The present study focuses on three major affective factors, which are motivation, anxiety, and self-confidence (Krashen, 1981). Three measures are used to assess learner motivation: (a) attitudes toward the L2, its speakers, and the learning situations; (b) intensity/effort extended in learning; and (c) the desire to learn the L2 (Gardner, 1985). In terms of foreign-language anxiety, a situational perspective is adopted. The key advantage of this perspective is that the respondents are required to make attributions of anxiety to particular sources (MacIntyre \& Gardner, 1991).

This study intends to reveal the linguistic and nonlinguistic outcomes of NS-NNS interaction and how individual Chinese ESL students make sense of their experiences of interaction in a natural setting. It considers the following research questions.

- What opportunities do the students have to interact with NSs in a natural setting?

- How does NS-NNS interaction influence students' life and study?

- What difficulties and barriers in interaction do students often experience?

\section{Methodology and Procedures}

This study applied an integrated method. First, a questionnaire was distributed to obtain quantified general descriptions of the NS-NNS interaction. Descriptive statistics such as frequencies and percentiles were calculated and reported. Then semistructured interviews were conducted with volunteer students to reveal how individuals make sense of their interaction experiences. Priority and emphasis were given to the qualitative inquiry, and students' attitudes and experiences were understood in context.

The target group of the present study were Chinese ESL students in Canada. Participants were selected on the basis of convenience from an ESL program at a public university. Having acquired permission from the ESL department, I entered the intermediate-to-high-level ESL classrooms to explain this study to the students, obtain consent (see Appendix C, Ethics Addendum), and collect data. At the opening stage, an anonymous questionnaire (Appendix A) was distributed, and 25 Chinese ESL learners completed their questionnaire. Students were asked to leave their contact information at the bottom of the questionnaire if they preferred to be interviewed later. Then at the second stage, on obtaining written consent, I conducted semistructured interviews (Appendix B) with eight volunteers. During the interview, both audiotaping and notetaking were used to record data. To facilitate most effective communicattion with the participants, the questionnaire and the interviews were all conducted in the participants' native language: Chinese. Interview data were later transcribed and translated into English. Speakers of both languages were consulted for translation accuracy. 
Twenty-five questionnaires were collected from 25 Chinese students in three classes. The participants consisted of 16 men and nine women aged 19-27, with most between 20 and 22. They had lived in Canada for two to 28 months. All participants had received formal language instruction in their home country and had finished high school. Except for a 27-year-old male student who had earned a bachelor's degree in China, all were studying ESL full time in preparation for entry to an undergraduate program in Canada. Three women and five men volunteered to be interviewed, and their average time spent communicating with NSs varied from 0-2 hours to over 30 hours per week. All names used are pseudonyms.

\section{Research Findings}

\section{Contact Length and Occasions}

As they were in Newfoundland, with the overwhelming majority of its residents (some 98\%) speaking English as their sole mother tongue, these ESL students were assumed to be surrounded by target language speakers after class. However, according to findings from the questionnaire, most Chinese students in the ESL program had only minimal contact with NSs outside their classroom. Among 25 of those who responded to the questionnaire, seven $(28 \%)$ students had an average of $0-2$ hours' communication with NSs per week; 14 (56\%) had 3-6 hours; two (8\%) had 7-10 hours; and another two (8\%) had more than 10 hours. Thus outside the classroom, 84\% of students spent fewer than seven hours per week communicating with NSs, which is less than one hour each day; and among them, one third spent no more than 25 minutes a day. Also, during the interview all eight informants said that in terms of the quantity of communication, they were dissatisfied with their current state and expressed a desire to have more contact with NSs outside the classroom.

In the questionnaire, the opportunity for interaction between students and NSs falls into four main categories, and students were asked to name one or several most frequent occasions when they had contact with NSs. The results are shown in Table 1.

\section{Attitudes Toward Interaction Overview}

In the questionnaire, students were asked to choose from a list of the positive features (see Question 3 in Appendix A), and another list of the negative features (see Question 4 in Appendix A) of communication with NSs according to their experiences. For each set of features, there were seven items, and students were allowed to choose more than one. The results for Questions 3 and 4 are shown in Tables 2 and 3 respectively.

The one student who answered other specified that it also helped to enhance his self-confidence and motivation in learning the language. There- 
2. chatting with friends, conversation partners, or host family/landlord

(Note: Conversation Partner is an ESL program that pairs international students with NSs to talk.)

3. school activities

fore, the top three positive features of communication with NSs were improvement in the language itself, ease and / or confidence in using the L2, and awareness of its culture and society.

The one student who answered other specified that she did not have enough vocabulary, but this may be placed under the first item too. Therefore, the top three negative features of communication with NSs were: limited opportunities, difficulty in finding conversation topics, and language problems.

In comparing Tables 2 and 3 , it is not difficult to find that the accumulated frequency (89) of positive features is much greater than that of negative features (43), which suggests that students' attitudes toward interaction with NSs were generally positive. In particular, among the 25 participants, 19 $(76 \%)$ selected more positive features than negative, five (20\%) selected an equal number of positive and negative features, and only one (4\%) student chose more negative features in the questionnaire.

The last two questions in the questionnaire (Questions 5 and 6 in Appen$\operatorname{dix}$ A) were designed to reveal further which of the negative features was considered worst for students' communication with NSs. The replies to Question 5 are shown in Table 4.

This shows that the language barrier was the main barrier and that lack of opportunity came in second place.

Table 2

Positive Features of Interaction

\begin{tabular}{llllllll}
\hline Item No. & 1 & 2 & 3 & 4 & 5 & 6 & 7 \\
\hline Frequency & 23 & 15 & 10 & 16 & 13 & 11 & 1 \\
Percentage & $92 \%$ & $60 \%$ & $40 \%$ & $64 \%$ & $52 \%$ & $44 \%$ & $4 \%$ \\
\hline
\end{tabular}


Table 3

Negative Features of Interaction

\begin{tabular}{llllllll}
\hline Item No. & 1 & 2 & 3 & 4 & 5 & 6 & 7 \\
\hline Frequency & 9 & 3 & 10 & 2 & 6 & 12 & 1 \\
Percentage & $36 \%$ & $12 \%$ & $40 \%$ & $8 \%$ & $24 \%$ & $48 \%$ & $4 \%$ \\
\hline
\end{tabular}

\section{Language as a Barrier and a Benefit}

In the questionnaire, most (23 of $25,92 \%)$ felt that their language skills improved through interaction, but at the same time, L2 proficiency was identified as one of the major barriers to communication with NSs. Zhao was one of four students among 25 who reported more than seven hours of after-class communication with NSs per week; he still remembered how little communication he was able to have on arrival because of his limited command of English:

When I first came, my landlord went to the airport and picked me up. He spoke very fast. The first week I stayed with him, he spoke 10 sentences, and the only thing I could catch was, he called my name and asked me for dinner, so I went, but the other words I didn't understand at all. He didn't feel like speaking to me, as he figured out my English was so poor. When I spoke English he completely had no idea what I was talking about. At that time, when I spoke I just put some English words together but in the wrong order, the sentence structure was still Chinese. Sometimes I had to write notes in order to communicate.

Students perceived L2 proficiency as a barrier to communication, and specifically, they mentioned problems with vocabulary and expressions being most substantial.

It's difficult when you want to articulate something but don't know how. I feel one thing is [because of] the vocabulary, and the other is expression. When you talk about something profound, like culture, you contemplate it in Chinese, but have to say in English, you have no idea

Table 4

The Greatest Barrier to Communication

\begin{tabular}{lllllll}
\hline Item No. & 1 & 2 & 3 & 4 & 5 & 6 \\
\hline Frequency & 14 & 7 & 6 & 9 & 6 & 0 \\
Percentage & $56 \%$ & $28 \%$ & $24 \%$ & $36 \%$ & $24 \%$ & 0 \\
\hline
\end{tabular}


what the exact words and expressions are ... Also, native speakers use a lot of expressions that I can't use or don't even know.

Incomprehensible words and expressions in a conversation often required NSs to repeat, explain, give examples, substitute by synonyms, or write points down for later consultations. Students felt that such interaction promoted their language skills and that it was particularly helpful for internalizing new words and expressions, as Zhao said,

Last time someone was talking about something, and used the word "skyrocket." It made me wonder "how is population related with rocket?" After they explained, I finally understood that "skyrocket" means "to increase rapidly" ... You know, the English we learned in China never taught oral expressions; they were all very formal. The idioms I presently know were all picked up from conversations with others.

Interaction with NSs may frequently help students to enlarge their vocabulary, but because memory is selective and usually requires repetition, consciousness is critical for vocabulary learning. For example, Liang mentioned that once his conversation partner talked about car parts by drawing a picture as an illustration. But because these words were not frequently used and Liang was not very interested in learning them, eventually none of the new words was retained.

All students mentioned how communication with NSs had helped them to improve their English-mostly in fluency, vocabulary, and expressionand for some in pronunciation too. But none expressly acknowledged their improvement in grammar as a benefit. Several students commented that "grammar is a piece of cake" for most Chinese students, as they have all learned it extensively in secondary school in China. They believed that customarily their written expression was better than their spoken expression. As an example, Zhao first came to Canada speaking ungrammatical and incomprehensible English, but his landlord was able to understand him when he tried to communicate in writing.

\section{Interaction and Affective Changes}

Fan recalled that seven months before when she had first arrived, she had ordered meals by pointing to the menu board and would order combos only. She did not dare to order items one by one, because she was afraid to make mistakes and afraid that people could not understand her. Such interaction made her feel that she had "lost face." But now she was comfortable with ordering, and she ordered what she really wanted instead of combos. I asked her how this had happened: was it because she could now speak English better? Fan explained, 
The most important reason is, you've been here for quite some time, you go to parties and get to know more and more native speakers, you talk to them, and little by little you feel it's really unnecessary to be so timid in front of them.

Through repeated interaction with NSs, Fan realized that there was no reason why she should feel fearful or hesitate to order foods that she really wanted or to do things she needed to do just because she could not speak the L2 perfectly. Although she still had problems with communication, now she had become more ready and willing to solve them through interaction. Just as Zhao put it, "The more you speak, the more courageous you become, and the more you speak, the better words and sentence structures you'll be using. Then you have more confidence, and you attempt to communicate more constantly with people."

Although transformation in mindset (or acculturation) was not an intended focus of investigation, during the interviews informants brought up this issue and believed that it was a positive outcome of interaction and was helpful in improving communication. Some changes such as being more open and bold or caring less about losing face were particularly beneficial for their L2 learning. According to Zhao, such changes might not be an immediate result of communication, but contact with NSs would exert an imperceptible influence on one's thinking.

[Regarding negotiating meaning] At first, I was also afraid, because they explained, but I was still confused, and I felt embarrassed to ask again. If you were in China, you would feel embarrassed if this happens, you always have that kind of thinking ... most Chinese are too traditional. I feel once we alter this, we'll-anyway, many people changed after they came here. I can't exactly tell what has changed, like personality, behavior, life style, sense of values, but all can be very different.

By saying "most Chinese are too traditional," Zhao meant that in traditional Chinese culture people always have many worries about how others feel and think about them. Being self-conscious, people tend to be passive rather than taking the initiative. When it comes to using the L2, they will avoid making mistakes and taking risks. Also, people are easily embarrassed when they encounter problems in communication and are likely to withdraw from negotiating meanings when they feel embarrassed. Having stayed in Canada for some time, Zhao and several other informants felt that they were now more independent and adventurous in their thinking and doing. Now they would adhere to their opinions and actions more firmly and care less about what other people might think of them. Before they came, none of them had expected such a change, but as they looked back they felt happy about it. 


\section{Limited Contact with NSs}

Students on average spent limited time communicating with NSs although they were in an English-speaking area. Because most students in this ESL program were from China, they mostly talked in Chinese during breaks, and in fact many shared houses with other Chinese students. Informants thus raised the issue of one's circle of acquaintances. They felt that by studying in this ESL program and living with other Chinese, they had few chances to get to know NSs. Such a circle obstructed their contact with other ethnic groups in and after school, and so it reduced their opportunities to use English.

Sometimes living with a host family or moving into a dormitory to share a suite with NSs can notably increase NNSs' contact with NSs. For example, Dong claimed that he was so introverted that he would not actively seek opportunities to speak English and would sometimes even try to avoid them. He had little interaction in English at school, but chatted frequently with his landlady, his landlady's boyfriend, and their neighbors because they were friendly and had become quite familiar to him. However, some students' interactions with the host family were limited to saying Hello every morning and night and a few words at the dinner table. Obviously living with NSs does not guarantee interaction. Both the students' and the host families' intention to interact is pivotal.

School activities are intended to provide casual and carefree communication environments for every student. For ESL students these can be great opportunities to practice English and to become involved in school. All informants agreed that every week there were various activities in school; the opportunities were great. But curiously, according to the questionnaire and interviews, most students attended hardly any of these activities. Some students went occasionally, but found them uninteresting. For example, Chen went to the Coffee Club (an event organized by the International Student Association, which aimed to bring international students together for chats) and some other activities several times. He felt that students went there for the sake of chatting, but once finished with self-introductions and some general topics, they did not have much to talk about. Students pointed out that there were few school activities where NNSs and NSs could really mingle.

Besides, because participation in activities was voluntary, sometimes students did not go simply because they "got lazy" and were not in the mood. They explained that in China students are under the "strict supervision" of teachers throughout elementary, junior high, and high school. They had been used to all kinds of rules and to being regulated to follow the rules. Now they could choose about many things, but often lacked the motivation and selfdiscipline to be active. Students suggested that it would be helpful if someone somehow could enforce their participation in activities. 


\section{Practical Difficulties}

When asked about problems with NS-NNS conversation, Zhao said, "Most times there weren't too many words, because you still don't know each other well, and don't know if the native speaker is willing to listen to you." Almost all informants reported that apart from their conversation partner and host family/landlord, they did not have other NS friends, and some were not even sure that their relationship with their conversation partner and landlord was close enough to be called "friends." They recounted that it was hard to maintain and develop friendship with NSs and that because of the unfamiliarity, it was difficult to find conversation topics.

Cultural distance is yet another challenge in trying to locate appropriate topics. Some topics are full of social, cultural, and historical background such as those about famous people, political issues, and even television programs. Because of this, any explanation involved can be complicated and time-consuming. For example, once Chen talked about the idea of "being filial towards parents" in Chinese culture, but did not know how to make this clear and explain to others why it is important to the Chinese.

Communication in English sometimes is mentally and physically demanding for NNSs. So despite their talkativeness in their native language, informants expected that NSs, being more capable in the language, would be more active in conversation and that they would not need to strive to keep the conversation flowing. They did not mind if they could not lead the conversation or play a major role. As Mao said,

I feel that to communicate is more demanding than to simply listen or speak, because in a moment we have to process and put together thoughts and expressions ... When you communicate with native speakers, you have an expectation. You hope that once a topic is found, he/she could say more, and you don't have to say too much, because that would be easier for you. Like two people communicating in Chinese, the one who's more talkative will lead the conversation. But when it comes to using English, which is not our native language, we have no competence to steer. So we always hope that he/she can talk more.

\section{Social Support}

All informants said that NSs in this province were mostly friendly. Compared with people in big cities, people here were warmer and showed more willingness to talk to foreigners. For example, when students had a problem with shopping or finding a place and asked for help, people would explain things to them and would repeat if they did not understand. Sometimes people would even take them where they wanted to go. It was generally 
agreed that if you took the initiative to talk to NSs, almost all would reply with politeness and patience.

On the other hand, informants encountered few NSs who would take the initiative to talk to them first, and they also complained about the inadequate effort that NSs sometimes made during interaction. Yu was one of the few informants who did not think that NSs were willing to communicate with her. Given that $\mathrm{Yu}$ had spent the greatest amount of time communicating with NSs, her response was somewhat surprising. She remarked,

No, I don't feel like this [most NSs are willing to communicate with me]. If you talk to them, they won't disregard you, and their attitude is fine, but usually they don't speak to you first. Besides, if you aren't finding topics, sometimes they won't try to find one and discuss with you. Examples are with those casual friends and classmates ... also, many conversation partners are not very outgoing people, and they don't know how to find topics. I suppose many of them still lack communication experiences with foreigners, and don't know what to talk about with people from other countries.

Several informants expressed hope for NSs to be more interactive so that they might benefit from the feedback NSs could provide, as Zhao said,

At first, he [conversation partner] would just listen to me. Then I told him that I hoped he could also tell me something, and if I make any grammar mistake or problematic sentence, he could correct me, otherwise I would think that they were all right. He agreed, and became better ... I don't like the feeling of doing all the talking, and after I finish, people don't have much response. Then I don't know what to say next, and how to step down. Communication should be interactive.

Informants had entirely diverse responses to the question "Do you feel that most NSs are willing to talk to you or not?" As I dug into the transcripts, I started to feel that perhaps students' answering either Yes or No, indicating satisfactory and unsatisfactory, was not really a contradiction. All these were because they had varied measures for "being willing to communicate." Some may think that being able to respond appropriately is good enough to pass, whereas others may think that NSs have to show their willingness by initiating conversations and actively contributing topics and feedback. With diverse measures, students had varied replies to this question. Looking at the complete testimony that each provided, I found that informants were generally satisfied with NSs' friendly attitudes, but were somehow dissatisfied with the initiation of and contributions that NSs made to conversations.

Informants found that compared with younger NSs, elderly people usually showed more interest in talking to them and were more likely to start a conversation. Having spare time was a prerequisite; and having more expe- 
rience, older people were probably more skilled at communicating with someone from another cultural background. Besides, they might also feel sorry for young people who had had to leave their family and country to study.

\section{Conclusions and Discussion}

\section{The Linguistic Outcomes of Communication}

In this study, the linguistic benefit of communicating with NSs was most obvious in terms of fluency, vocabulary, and expression, and sometimes pronunciation. There were no doubts about fluency. Then during communication, students were exposed to new words and expressions, and through interaction these words and expressions made sense and some were internalized. Finally, those students who cared about pronunciation also paid attention to the difference between NSs' tongue and theirs. However, except for fluency, the other two benefits were frequently associated with the students' intention and awareness, and thus were situational and selective. This finding is in accordance with the assertion that negotiation may be beneficial only to certain learners (Mackey \& Philp, 1998), with the nuance that it is beneficial to certain learners on certain occasions.

Most of these intermediate ESL students from China had completed high school before arrival. Through years of formal education they had systematically learned English grammar. Although the students' perceived that their competence in grammar was relatively high, they still continually made mistakes in speaking and writing. They still did not know nor had internalized some of the rules. However, none of the informants claimed that their grammar knowledge had improved through interaction, or if it had, the growth was too minor to be acknowledged. This finding is in agreement with the argument that when learners communicate in the L2, they fail to notice non-target-like features in their interlanguage unless indicated explicitly (Schmidt \& Frota, 1986). Therefore, the results of the present study once again cast doubt on the suggestion that interaction leads to acquisition.

\section{The Nonlinguistic Outcomes of Communication}

A dynamic relationship between anxiety/confidence and interaction was found in this study. As predicted by the socio-educational model (Gardner, 1985), L2 anxiety and confidence considerably influenced students' interaction with NSs, and conversely, interaction with NSs could gradually modify students' general anxiety and confidence levels. In addition, some students reported and appreciated acculturation in the sense of risk-taking and openmindedness. Although acculturation is beyond the scope of the current study, such an account is in accordance with the assertion that by engaging in the practices of a community, people not only learn new concepts, but also 
transform themselves and construct new identities in that context (Lave, 2004).

Another affective variable examined was motivation, and three measures were proposed (Gardner, 1985) to use in assessing learner motivation: attitudes toward the L2, its speakers, and the learning situations; the desire to learn; and the intensity/effort expended on learning. In this study, most students maintained positive attitudes toward communication with NSs as demonstrated by their acknowledgment of the associated benefits and their desire to have more contact with NSs. In either the questionnaire or the interview, most students emphasized and elaborated on the benefits of interaction rather than their dislike of it. Even some informants who had the least contact with NSs felt and believed such interaction could do them much good. The difference lay in the fact that students who had more contact with NSs were able to give specific examples to illustrate their benefits.

In terms of desire, all informants exhibited considerable desire to have more contact with NSs. Many admitted that their participation in activities and socialization with NSs were somehow driven by a language-learning motivation, but in the meantime, they also hoped to integrate better by making friends with NSs. These ESL students all had plans for completing their bachelor's, master's, or further study in Canada, which would take many years. They hoped that by socializing with NSs, they could integrate into society and spend quality time abroad.

However, it was interesting to discover that a significant gap frequently existed between students' attitude toward/desire for communication and their interaction intensity. Several enthusiastically expressed their acknowledgment of communication benefits and their wish to have more contact with NSs, but at the same time admitted that they actually did not make much effort to interact. One problem was with the students' determination. As mentioned above, most Chinese ESL students are young and have been under close supervision by teachers and parents before coming to Canada. Now, with so much freedom, some felt lost and lacked the determination and self-discipline to go out of their way to use English.

Other reasons for the discrepancy could be students' personalities, language barriers, limited opportunities, and weak social support from NSs. For these reasons sometimes they were too shy or self-conscious to speak; other times they found it hard to have an interlocutor and even harder to find an interactive, cooperative NS with whom to communicate; and once the conversation was started, difficulties with finding topics and with the language itself were also expected. Therefore, although students commonly held positive opinions toward interaction, they might display inadequate intensity.

Using the concept of locus of control for interpretation, I found that the informants were generally objective and self-reflective. They pointed out those barriers that inhibited their communication, and also expressed the 
importance of individual effort. Several informants reflected that they did not try hard enough. Most believed that because NS-NNS communication was primarily in the interest of the NNS (the L2 learner), it was their responsibility to seek opportunities and to take an active role in conversations. Thus most students expressed overall satisfaction with their social support, although they said that few NSs would take the initiative to talk to them, and many NSs were not interactive.

\section{Interaction is Socially Bounded}

Just as Norton (2000) criticized the premise that the language-learner's access to the L2 is a function of individual motivation, the theory of social support shed light on how to understand the gap between these students' attitudes/desires and their interaction intensity, as observed in the present study. It was found that to some extent the students were able to choose whether they would interact with NSs, so that individual differences and motivation did play a role in their access to the L2. However, except for one girl who had a Canadian boyfriend and who reported over 30 hours per week communicating with NSs, the other participants all had fewer than 10 hours, although their personality or intensity might vary. As pointed out, even in situations where the learner is surrounded by speakers of the target language, social support is critical and cannot be taken for granted (Noels, 2001).

In addition, this study found that students' anxiety, self-confidence, and interaction intensity were not consistent across varied communication situations and interlocutors. This finding complemented the critical perspective, which argues that a language-learner's affective filter is not an inherent trait, but one that is socially constructed with and by the experiences of the learner (Norton, 2000).

\section{Further Implications}

Informants related some negative examples that they had witnessed, noting that a few ESL students had been in Canada for months or years, but had lived as hermits. They had almost zero contact with NSs and would go out only if accompanied by other Chinese so that others could speak for them. They felt unusually lonely, lacked self-esteem, and performed below average in class. They were also frequently absent from class. Eventually, some went back to China without going to college, and others continued struggling in the ESL program.

In such extreme cases, resistance to communication and interaction had substantially damaged the students' well-being in the new country. After all, when people speak, they are not only exchanging information; they are continually reorganizing a sense of who they are and how they relate to the social world (Norton, 2000). Thus in addition to the prevalent linguistic 
analysis, it would be reasonable and rewarding to integrate the affective and social perspectives into future study of the role of interaction.

\section{Acknowledgments}

I express my sincere gratitude to Barbara Burnaby for her guidance during the study and insightful comments on early drafts of this article. In addition, I thank Robert Anna for reading and editing the draft.

\section{The Author}

Guang $\mathrm{Xu}$ is a lecturer in English and an academic adviser at Sydney Institute of Language and Commerce, Shanghai University, China.

\section{References}

Ajzen, I., \& Fishbein, M. (1980). Understanding attitudes and predicting social behavior. Englewood Cliffs, NJ: Prentice-Hall.

Baker, S.C., \& MacIntyre, P.D. (2000). The role of gender and immersion in communication and second language orientations. Language Learning, 50, 311-341.

Clément, R., Baker, S.C., \& MacIntyre, P.D. (2003). Willingnesss to communicate in a second language: The effects of context, norms and vitality. Journal of Language and Social Psychology, 22, 190-209.

Ellis, R. (1995). Modified oral input and the acquisition of word meanings. Applied Linguistics, $16,409-441$.

Ellis, R. (1999). Learning a second language through interaction. Philadelphia, PA: John Benjamins.

Gardner, R.C. (1979). Social psychological aspects of second language acquisition. In H. Giles \& R. St. Clair (Eds.), Language and social psychology (pp. 193-220). Oxford, UK: Basil Blackwell.

Gardner, R.C. (1983). Learning another language: A true social psychological experiment. Journal of Language and Social Psychology, 2, 219-239.

Gardner, R.C. (1985). Social psychology and second language learning. London: Edward Arnold.

Gardner, R.C., \& MacIntyre, P.D. (1992). A student's contributions to second language learning. Part I: Cognitive variables. Language Teaching, 25, 211-220.

Krashen, S.D. (1981). Second language acquisition and second language learning. New York: Prentice-Hall.

Krashen, S.D. (1994). The input hypothesis and its rivals. In N.C. Ellis (Ed.), Implicit and explicit learning of languages (pp. 45-77). New York: Academic Press.

Lave, J. (2004, February). Learning as changing practice. Paper presented at Vanderbilt University Visiting Scholars Speakers Series, Nashville.

Long, M.H. (1983). Native speaker/non-native-speaker conversation and the negotiation of comprehensible input. Applied Linguistics, 4, 126-141.

Long, M.H. (1996). The role of the linguistic environment in second language acquisition. In W.C. Ritchie \& T.K. Bhatia (Eds.), Handbook of second language acquisition (pp. 413-468). San Diego, CA: Academic Press.

MacIntyre, P.D. (2003, June). Willingness to communicate in the second language: Proximal and distal influences. Paper presented at the 33rd annual conference of the Canadian Association of Applied Linguistics, Halifax. Retrieved February 6, 2010, from: http:/ /faculty.uccb.ns.ca/pmacintyre/research_pages/other_files/WTC_handout.htm

MacIntyre, P.D., Baker, S.C., Clément, R., \& Conrod, S. (2001). Willingness to communicate, social support, and language-learning orientations of immersion students. Studies in Second Language Acquisition, 23, 369-388. 
MacIntyre, P.D., Baker, S.C., Clément, R., \& Donovan, L.A. (2003). Talking in order to learn: Willingness to communicate and intensive language programs. Canadian Modern Language Review, 59, 589-607.

MacIntyre, P.D., Dörnyei, Z., Clement, R., \& Noels, K.A. (1998). Conceptualizing willingness to communicate in a L2: A situational model of L2 confidence and affiliation. Modern Language Journal, 82, 545-562.

MacIntyre, P.D., \& Gardner, R.C. (1991). Language anxiety: Its relationship to other anxieties and to processing in native and second languages. Language Learning, 41, 513-534.

Mackey, A. (1999). Input, interaction, and second language development: An empirical study of question formation in ESL. Studies in Second Language Acquisition, 21, 557-587.

Mackey, A., \& Philp, J. (1998). Conversational interaction and second language development: Recasts, responses, and red herrings? Modern Language Journal, 82, 338-356.

Nation, I.S.P. (2001). Learning vocabulary in another language. Cambridge, UK: Cambridge University Press.

Noels, K.A. (2001). New orientations in language learning motivation: Towards a model of intrinsic, extrinsic, and integrative orientations. In Z. Dornyei \& R. Schmidt (Eds.), Motivation and second language acquisition (pp. 43-68). Honolulu, HI: University of Hawai'i Second Language Teaching and Curriculum Centre.

Norton, B. (2000). Identity and language learning: Gender, ethnicity, and educational change. Harlow, UK: Longman/Pearson Education.

Philp, J. (2003). Constraints on "noticing the gap": Nonnative speakers' noticing of recasts in NS-NNS interaction. Studies in Second Language Acquisition, 25, 99-126.

Pica, T. (1992). The textual outcomes of native speaker-non-native speaker negotiation: What do they reveal about second language learning? In C. Kramsch \& S. McConnell-Ginet (Eds.), Text and context (pp. 198-237). Cambridge, MA: Heath.

Pica, T. (1994). Research on negotiation: What does it reveal about second-language learning conditions, processes, and outcomes? Language Learning, 44, 493-527.

Schmidt, R.W., \& Frota, S.N. (1986). Developing basic conversational ability in a second language: A case study of an adult learner of Portuguese. In R.R. Day (Ed.), Talking to learn: Conversation in second language acquisition (pp. 237-326). Rowley, MA: Newbury House.

Schumann, J.H. (1994). Where is cognition? Emotion and cognition in second language acquisition. Studies in Second Language Acquisition, 16, 231-242.

Swain, M. (1985). Communicative competence: Some roles of comprehensible input and comprehensible output in its development. In S.M. Gass \& C.G. Madden (Eds.), Input in second language acquisition (pp. 235-53). Rowley, MA: Newbury House.

Varonis, E.M., \& Gass, S.M. (1985). Non-native/non-native conversations: A model for negotiation of meaning. Applied Linguistics, 6(1), 71-90.

White, L. (1987). Against comprehensible input: The input hypothesis and the development of second-language competence. Applied Linguistics, 8, 95-110.

Yashima, T. (2002). Willingness to communicate in a second language: The Japanese EFL context. Modern Language Journal, 86, 54-66.

Yashima, T., Zenuk-Nishide, L., \& Shimizu, K. (2004). The influence of attitudes and affect on willingness to communicate and second language communication. Language Learning 54, 119-152.

\section{Appendix A \\ Questionnaire (English Translation)}

General Information:

Age: ;Gender: ; ESL level: 
Length of stay in an English speaking country or region:

months

\section{Questions:}

1. In which of the following occasions do you MOST OFTEN communicate with native English speakers outside of the classroom? (You may choose more than one)

(1) Chat with friends.

(2) Go shopping; get things done in school or outside.

(3) School activities.

(4) Church or community events.

(5) Other (please indicate)

2. On average and per week, how many hours in total do you spend in communicating with native English speakers outside of the classroom?
(1) 0-2 hours.
(2) 3-6 hours.
(3) 7-10 hours.
(4) More than 10 hours, which is hours (please specify).

3. According to your experiences, what are the positive features of communication with native English speakers? (You may choose and add more than one)

(1) It improves my listening, speaking English, and other language skills.

(2) It increases my knowledge of local culture and society.

(3) It gives me some useful information about life and school here.

(4) It helps to overcome my anxiety in using English.

(5) It helps me to make more friends.

(6) It enables me to better integrate into the new environment and the country.

(7) Other (please specify)

4. According to your experiences, what are the negative features of communication with native English speakers? (You may choose and add more than one)

(1) My English is not good enough to talk to native speakers.

(2) I am rather anxious when speaking with native speakers.

(3) We don't have much in common to talk about.

(4) Not many native speakers are willing to talk to me.

(5) It's hard to make friends with native speakers.

(6) There aren't many opportunities to get to know native speakers and talk to them.

(7) Other (please specify)

5. What is the greatest barrier to your communication with native speakers outside of classroom?

(1) Language barriers.

(2) Social and culture barriers.

(3) Psychological barriers.

(4) Lack of opportunity to interact with them.

(5) Not many native speakers take the initiative or are willing to interact with foreign students.

(6) Other (please indicate)

6. Please briefly describe how this greatest barrier has impeded your communication:

\section{Appendix B}

\section{Semistructured Participant Interview (English Translation)}

\section{A. General background}

Which part of China are you from? 
What made you come here?

How long have you been in Canada?

How long will you stay?

\section{B. Experiences communicating with native English speakers}

Can you describe the situations when you communicate with native English speakers outside of the classroom?

Can you think of some situations where you enjoyed talking to native speakers?

Can you think of some situations where you felt uncomfortable talking to them?

Considering the role you play in conversations, do you feel it is different to talk to native English speakers?

\section{Attitudes toward communication with native speakers}

According to your experiences, are there any advantages of communication with native English speakers?

Are there any disadvantages of such communication?

Evaluating the advantages and disadvantages, do you think such communication is important or unimportant?

In general, how do you like your experiences talking to native English speakers?

\section{Effort to communicate}

Do you try to participate in some activities so that you can communicate with native speakers? What do you think of these programs or activities?

In your daily life, do you take the initiative to communicate with native speakers? Why/ Why not? In what situations would you do so?

\section{E. Desire to communicate}

Are you willing to talk to native English speakers or do you try to avoid such occasions? Is there any difference when your interlocutor is a friend, acquaintance, stranger, a student, a professor, etc.?

Do you want to have more communication with native English speakers outside of the classroom?

\section{F. Social support, difficulties, and satisfaction}

Do you feel most native speakers are willing to talk to you or not?

Are you satisfied with the opportunities that you have to communicate with native speakers? What kinds of difficulties or barriers do you have in the communication?

How do you like the school and living in here?

\section{Appendix C Ethics Addendum}

The following two paragraphs are adapted from the consent form of the study. In the consent form, information that reveals the purpose of the study, the procedure of the study, and the significance of the study is included. In addition, prospective participants are informed about the possible inconveniences and how their identities and rights will be protected during and after the study.

Your participation in the study is significant and beneficial in many ways ... However, participation in the study may also bring you some inconveniences. For example, it will take you some time to fill out the questionnaire, and the interviews can be particularly time-consuming; having you talk about the problems you have when interacting with native speakers may make you feel uncomfortable, etc. 
Participation in the study is voluntary, and you may withdraw from the study at any time. All information obtained from you in this study will remain confidential and will be disclosed only with your permission. By using pseudonyms for all places and interviewees, I will protect you and this university from being identified. Collected data will be stored in a safely locked case and will be destroyed after five years. Results from the study will be available to every participant upon request. If you have any questions about this study or your participation in it, please call me at ${ }^{* * *}$ or E-mail me at ${ }^{* * *}$. If you have ethical concerns about the research (such as the way you have been treated or your rights as a participant), you may contact our school ethics committee at ${ }^{* * *}$. 